\title{
RANCANG BANGUN SISTEM PELAPORAN BONGKAR RAMPUNG KWH LISTRIK DAN LAYANAN KHUSUS BERBASIS WEB PADA PT PLN (PERSERO) ULP SENGKANG
}

\author{
Farida Yusuf*, Firmansyah Ibrahim, Hasri Ainun Syam \\ Jurusan Sistem Informasi \\ Fakultas Sains dan Teknologi Universitas Islam Negeri Alauddin Makassar \\ J1. Sultan Alauddin No. 63, Kabupaten Gowa, Sulawesi Selatan. 92113 \\ *E-mail: faridayusuf19@gmail.com
}

\begin{abstract}
Abstrak: Penelitian ini dilatarbelakangi oleh tidak efektif dan efisiennya dalam pelaporan bongkar rampung kwh listrik dan layanan khusus pada PT PLN (Persero) ULP Sengkang khususnya bagian Pelayanan Pelanggan dan Administrasi (PAD) memerlukan data-data laporan yang ada di lima kantor pelayanan dengan turun langsung menyerahkan berita acara yang membutuhkan banyak waktu dan tenaga. Setelah datanya diterima, dilakukan penginputan ulang data yang berukuran besar dalam bentuk hardcopy. Tujuan dalam penelitian ini adalah untuk membuat sistem pelaporan bongkar rampung kwh listrik dan layanan khusus pada PT PLN (Persero) ULP Sengkang. Jenis penelitian yang digunakan ialah kualitatif serta pengembangan aplikasinya menggunakan metode waterfall. Pengumpulan data menggunakan metode observasi, wawancara, dan studi pustaka. Sistem dibuat menggunakan bahasa pemrograman $P H P, M y S Q L$ sebagai basis datanya serta menggunakan metode pengujian Blackbox. Hasil penelitian ini menghasilkan sistem pelaporan bongkar rampung kwh listrik dan layanan khusus berbasis website memudahkan PT PLN (Persero) ULP Sengkang untuk memeriksa laporan yang masuk dari pegawai yang ada di lima kantor pelayanan yang telah berjalan dengan baik sesuai dengan fungsinya. Serta menghemat biaya, waktu dan tenaga. Hal ini dibuktikan berdasarkan kuesioner terdiri dari 10 pertanyaan dan disebar ke 30 responden diperoleh hasil akhir rata-rata total persentase sebanyak $81,5 \%$ artinya responden sangat setuju dengan sistem tersebut.
\end{abstract}

Kata Kunci: bongkar rampung, layanan khusus, $M y S Q L$, pelaporan, $P H P$

\section{PENDAHULUAN}

โ

istrik adalah faktor terpenting dalam membantu kinerja pembangunan dan kemajauan suatu negara, baik dari segi ekonomi maupun sosial, kualitas listrik sangat mempengaruhi kemajuan dan keberhasilan pembangunan dalam suatu negara, termasuk Indonesia (Jaka, 2019). Oleh karena listrik adalah sumber daya siap pakai yang dikonversi dari energi primer menggunakan teknologi. Seiring dengan laju pesat teknologi dan ilmu pengetahuan, listrik pun berkembang menjadi kebutuhan primer, ini menandakan bahwa kebutuhan masyarakat akan penggunaan listrik memang sangat tinggi.

Perusahaan Listrik Negara (PLN)/PT PLN (Persero) merupakan perusahaan Badan Usaha Milik Negara atau yang dikenal dengan BUMN yang mengurus semua bagian kelistrikan yang terdapat di Indonesia, melalui visi agar "Diakui sebagai perusahaan kelas dunia kang berkembang, unggul dan terpercaya dengan bertumpu pada potensi insani" serta PT PLN (Persero) berkomitmen agar dapat menerangi seluruh Nusantara (Huda, 2019). PT PLN (Persero) ULP Sengkang singkatan dari Unit Layanan Pelanggan Sengkang merupakan nama baru dari Rayon Sengkang, salah satu ULP terbaik yang dimiliki oleh PT PLN yang dibawahi oleh UP3 Watampone.

Salah satu pekerjaan yang belum dilengkapi dengan sistem ialah pelaporan bongkar rampung KWH listrik dan layanan khusus. Bongkar rampung merupakan suatu proses pembongkaran terhadap Alat Pengukur dan Pembatas (APP), biasanya masyarakat awam menyebutnya dengan KWH listrik. Proses ini berlanjut apabila pelanggan melakukan tunggakan rekening listrik, rumah kosong yang listriknya sudah tidak terpakai lagi, atau ingin pindah rumah maka dilakukan proses pembongkaran KWH Listrik dan apabila pelanggan melakukan pelunasan tunggakan rekening listrik atau rumah baru maka dilakukan proses perampungan KWH Listrik. 
Permasalahannya yaitu ketika pegawai-pegawai kantor pelayanan ini melakukan pelaporan dengan turun langsung ke PT PLN (Persero) ULP Sengkang untuk menyerahkan berita acara bongkar rampung dan layanan khusus yang diperlukan, dan jarak yang dibutuhkan antara PT PLN (Persero) ULP Sengkang dengan 5 kantor pelayanan ini cukup jauh. Hal ini menyebabkan pegawai kantor pelayanan membutuhkan banyak waktu untuk melakukan pelaporan sehingga tidak efektifnya dan efisiennya waktu dan tenaga yang digunakan yang berdampak pada kinerja pegawai.

Permasalahan selanjutnya yaitu ketika Bagian Pelayanan Pelanggan dan Administrasi telah mendapatkan data yang dibutuhkan, namun data yang didapatkan dalam bentuk hardcopy sehingga menyebabkan pegawai harus menginput ulang data yang berukuran besar. Hal tersebut juga menyebabkan Bagian Pelayanan Pelanggan dan Administrasi memerlukan waktu yang lama dalam melakukan pemeriksaan laporan. Data yang dalam bentuk hardcopy juga menyebabkan pemborosan kertas dan banyak terdapat kertas-kertas yang menumpuk di PT PLN (Persero) ULP Sengkang.

\section{METODE PENELITIAN}

Dalam melakukan penelitian ini, jenis penelitian yang dipilih yaitu metode kualitatif. Metode kualitatif hanya mendeskripsikan data apa adanya dan menjelaskan data atau kejadian dengan kalimat-kalimat penjelasan secara kualitatif. Lokasi penelitian ini yaitu PT PLN (Persero) ULP Sengkang Jl. Jend Sudirman No. 06, Sengkang, Kabupaten Wajo, Sulawesi Selatan.

Pendekatan yang dilakukan dalam penelitian ini yaitu pendekatan saintifik yakni suatu pendekatan yang didasarkan pada ilmu pengetahuan dan teknologi yang telah dirancang sedemikian rupa untuk menemukan, mengidentifikasi serta merumuskan masalah.

Sumber data yang digunakan dalam penelitian ini yaitu data primer, yang langsung diperoleh dari sumber asli kemudian diolah sendiri oleh peneliti langsung dari subjek atau objek peneliti dan wawancara dengan salah satu pihak PT PLN (Persero) ULP Sengkang. Selain itu, penelitian ini juga berlandaskan pada literasi-literasi seperti jurnal, buku, karyaa ilmiah penelitian terdahulu yang memiliki keterkaitani pada penelitian ini serta sumber-sumber data online atau internet.

Pada penelitian ini peneliti menggunakan beberapa metode dalam pengumpulan data, yaitu antara lain:

a. Observasi: Observasi yang dilakukan ialah dengan mengamati secara langsung keadaan yang ada di PT PLN (Persero) ULP Sengkang.

b. Wawancara: Dalam penelitian ini penulis atau interviewer melakukan wawancara kepada narasumber Ibu Irawati selaku Supervisor Pelayanan Pelanggan dan Administrasi (PAD) dan Kakak Myana Reno Andhana selaku Staf Pelayanan Pelanggan dan Administrasi (PAD) dimana jadwal waktu wawancara mengikuti waktu laung dari narasumber.

c. Studi Pustaka: Dalam tahapan ini penulis mencari teori-teori yang saling berkesinambungan dengan penilitian ini yang didapat dari referensi buku-buku di perpustakaan kampus serta dari jurnal secara online imelalui internet. Setelah informasi didapat melalui beberapa referensi lalu digunakani dalam penyusunan landasan teori, metodologi penelitian dan juga dalam pembuatan rancangan sistem.

Pada penelitian ini, metode pengembangan sistem yang digunakan adalah waterfall. Waterfall merupakan salah satu metode dalam SDLC yang mempunyai ciri khas, pengerjaan setiap tahap dalam waterfall harus diselesaikan terlebih dahulu sebelum melanjutkan ke tahap selanjutnya. Metode waterfall adalah pengerjaan dari suatu sistem dilakukan secara berurutan atau secara linear. 


\section{HASIL DAN PEMBAHASAN}

1. Analisis Sistem yang Sedang Berjalan

Analisis sistem yang sedang berjalan adalah uraian mengenai sistem yang diamati yang sedang berjalan saat ini, sehingga kekurangan dan kelebihan dapat diketahui. Hal ini bertujuan untuk membandingkan kinerja sistem yang telah ada dengan sistem yang akan diusulkan atau dengan kata lain, untuk mengetahui lebih jelas bagaimana cara kerja sistem tersebut dan masalah yang dihadapi sistem untuk dijadikan landasan usulan perancangan analisa sistem baru yang dapat digambarkan dengan Diagram Alir Dokumen (flowmap). Flowmap dari sistem yang sedang berjalan ditunjukkan pada Gambar 1.

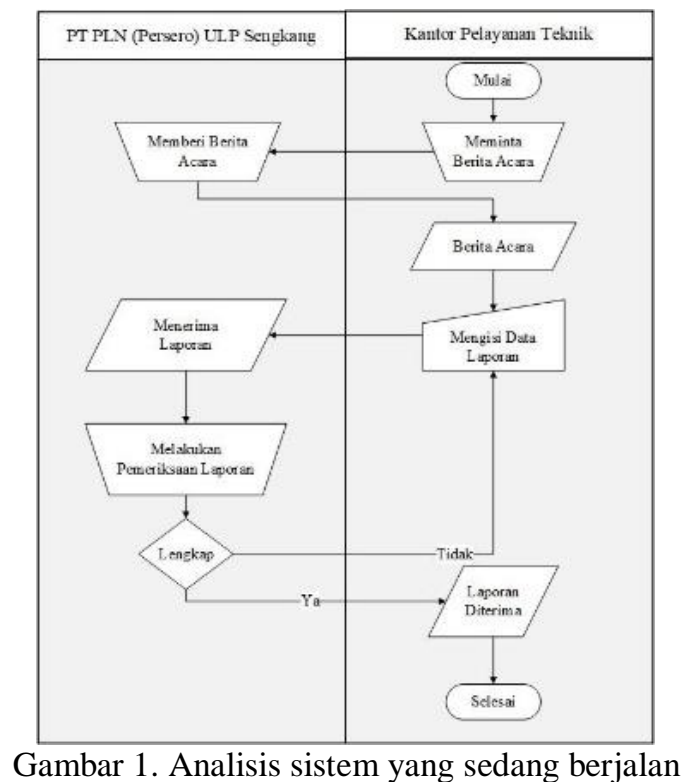

2. Analisis Sistem yang Diusulkan

Sistem yang diusulkan akan dirancang oleh peneliti dengan penekanan khusus terhadap pembangunan atau perancangan aplikasi berbasis website yang diharapkan dan mampu memudahkan dalam membantu kelancaran jalannya sistem pelaporan bongkar rampung kwh listrik dan layanan khusus. Flowmap dari sistem yang diusulkan ditunjukkan pada Gambar 2.

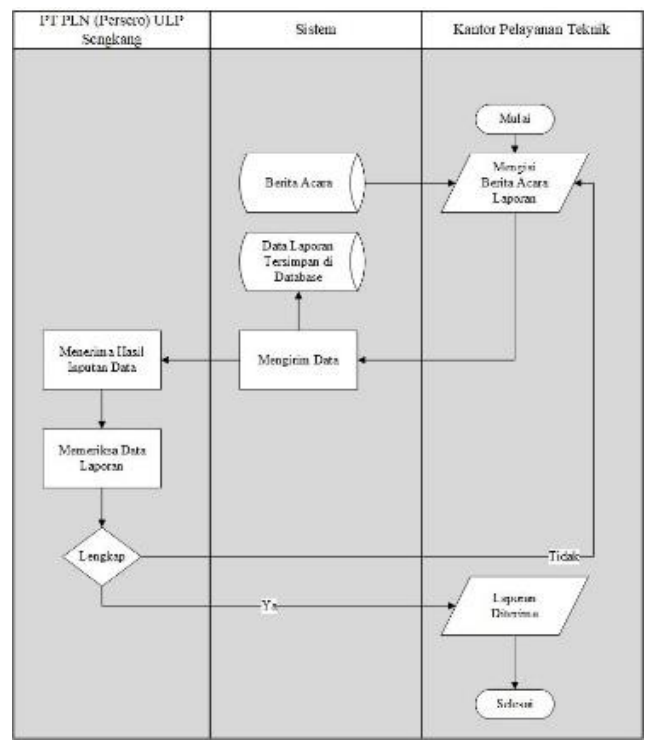




\section{Desain Perancangan Sistem}

a. Data Flow Diagram (DFD)

a) Diagram Konteks

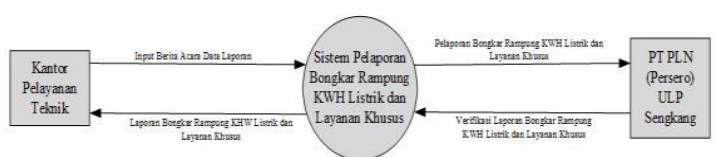

Gambar 3. Diagram konteks

b) Diagram Level 0

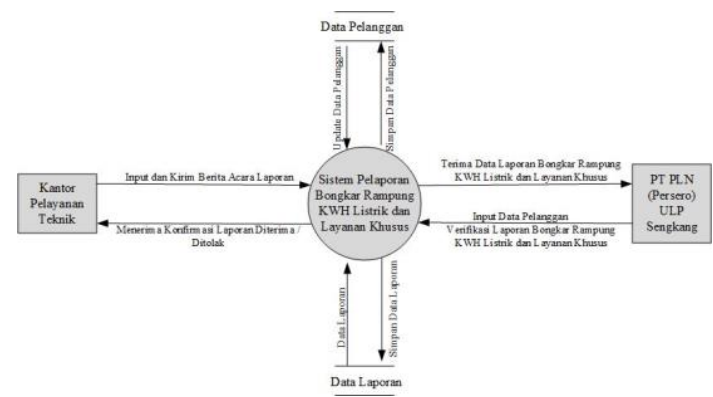

c) Diagram Level 1

Gambar 4. Diagram level 0

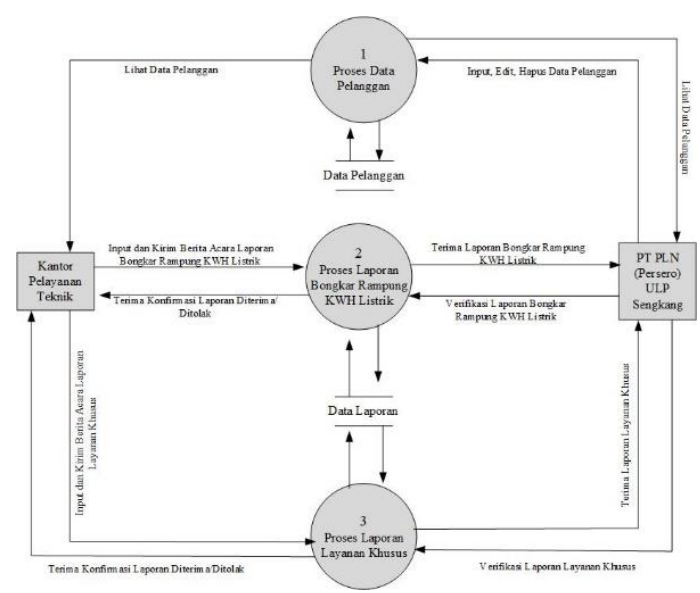

Gambar 5. Diagram level 1

d) Diagram Level 2

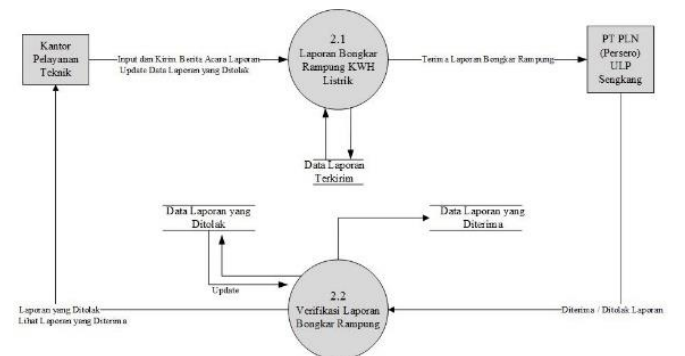

Gambar 6. Diagram Level 2 
e) Diagram Level 3

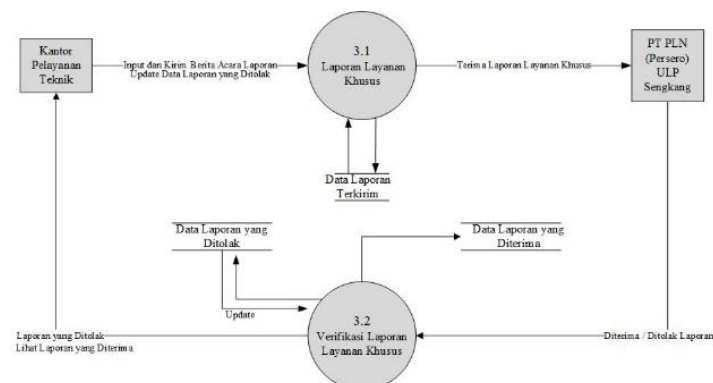

Gambar 7. Diagram Level 3

b. Entity Relationshio Diagram (ERD)

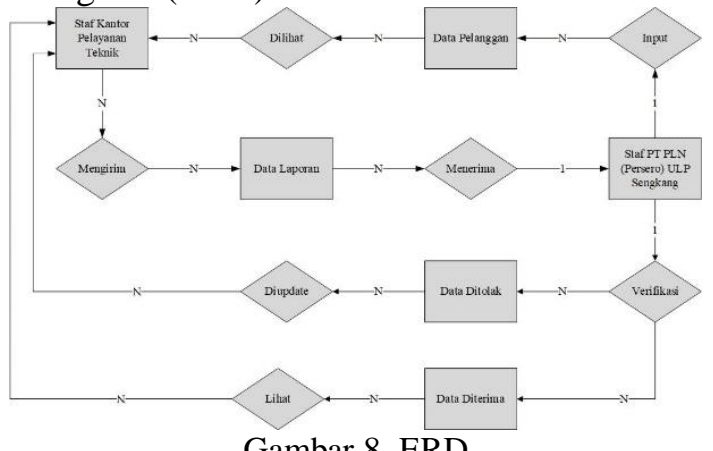

c. Flowchart

Gambar 8. ERD

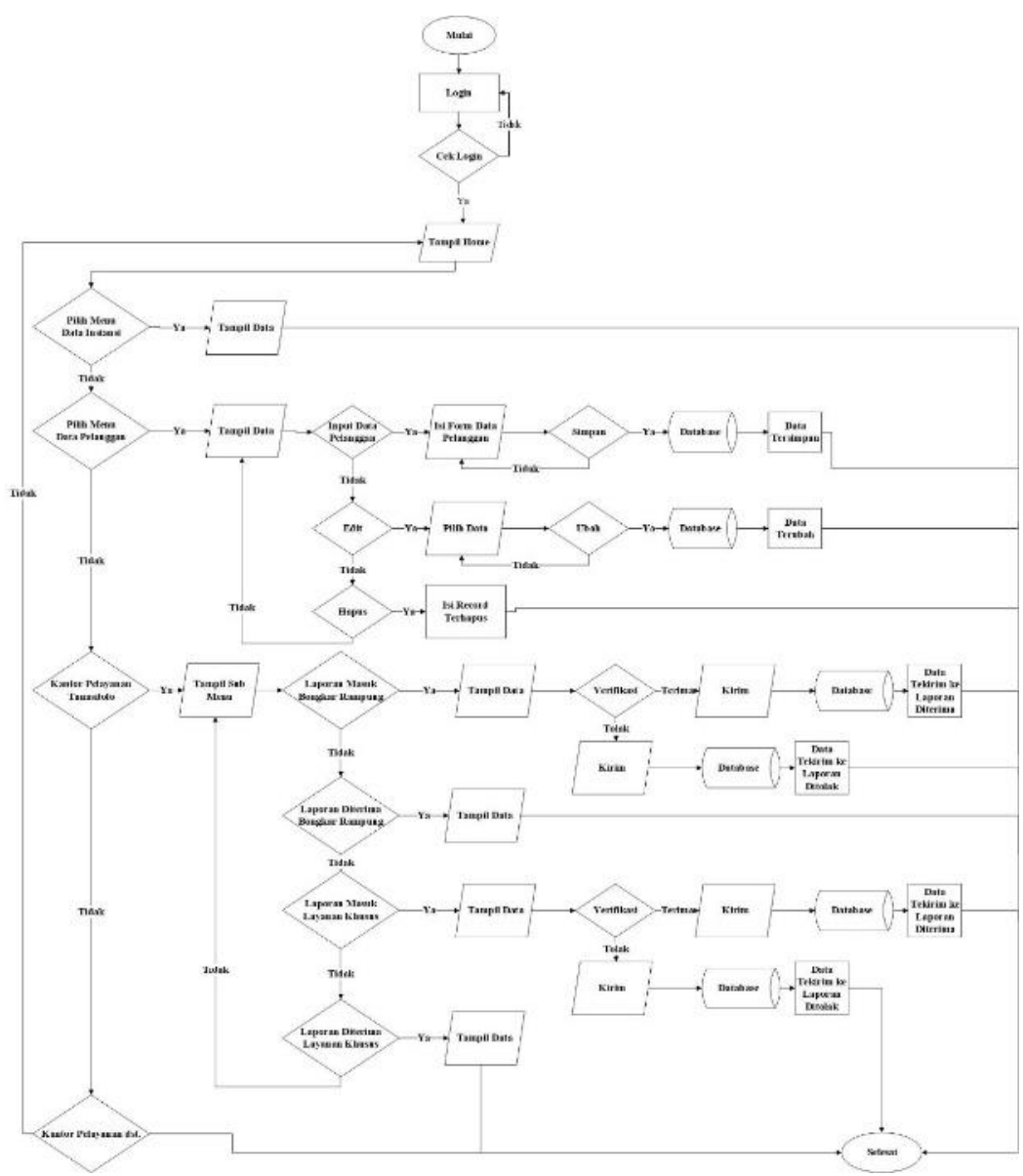

Gambar 9. Flowchart login super admin 
Pada Gambar 9 tersebut adalah gambaran proses sistem ketika login sebagai super admin atau PT PLN (Persero) ULP Sengkang, dimana alur sistem yang pertama yaitu login. Setelah berhasil login maka akan menampilkan menu home atau halaman utama, menu-menu laporan dan sebagainya. Di mana masing-masing fungsi menu tersebut dapat dilihat pada gambar diatas. Dan ketika login sebagai pihak Pelayanan Teknik hampir sama, hanya saja berbeda yaitu dari segi tampilan menu.

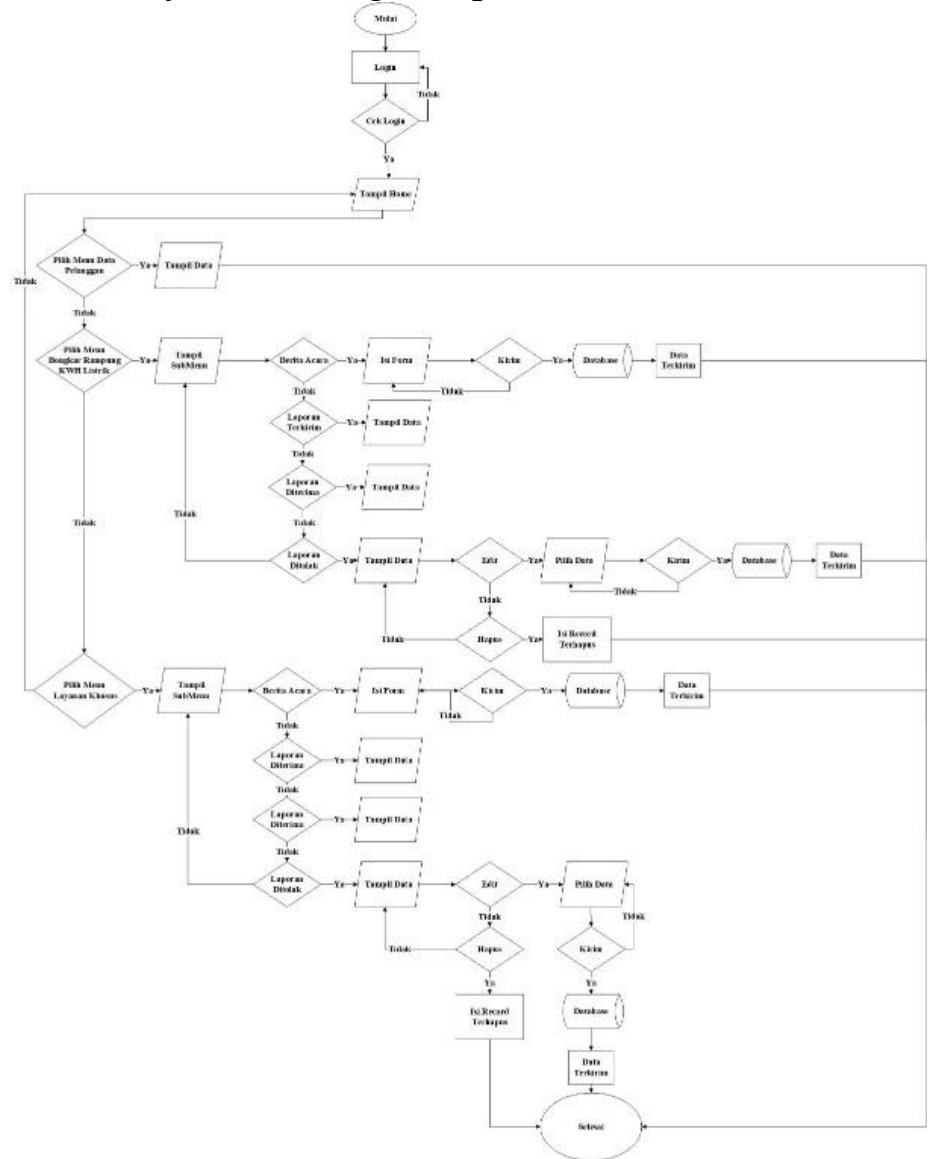

4. Implementasi Sistem

Gambar 10. Flowchart login admin

a. Tampilan Halaman Login

Tampilan halaman login merupakan halaman untuk super admin (PT PLN (PERSERO)

ULP Sengkang) dan setiap perwakilan lima kantor pelayanan teknik untuk login ke dalam sistem dengan terlebih dahulu memasukkan username dan password kemudian memilih tombol login atau menekan enter pada keyboard.

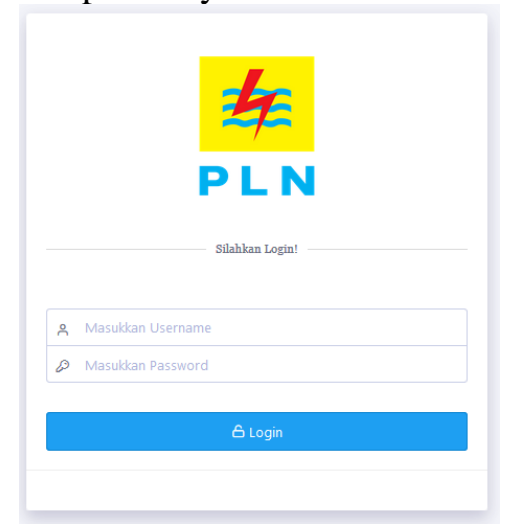

Gambar 11. Tampilan halaman login 
b. Tampilan Halaman Utama Super Admin

Tampilan halaman utama super admin merupakan tampilan awal ketika sukses login sebagi super admin/PT PLN (Persero) ULP Sengkang. Halaman ini menampilkan total laporan masuk bongkar rampung KWh listrik dan layanan khusus.

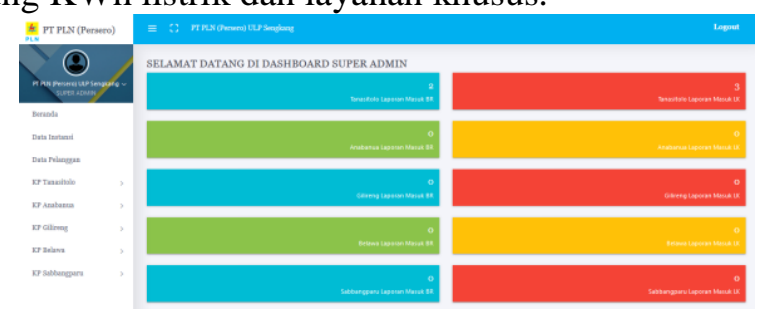

Gambar 12. Tampilan halaman utama super admin

c. Tampilan Menu Data Instansi

Tampilan menu data instansi merupakan halaman yang menampilkan data-data lima Kantor Pelayanan Teknik.

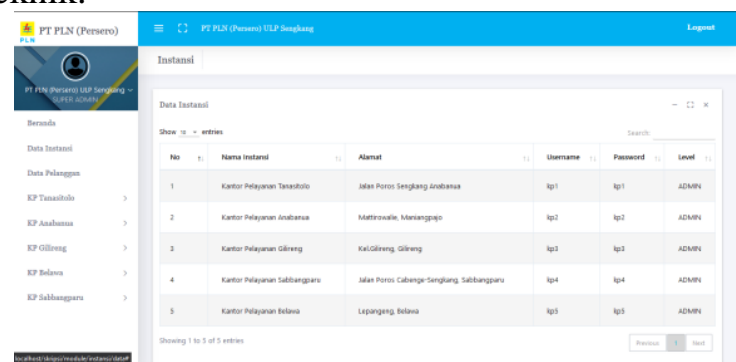

Gambar 13. Tampilan menu data instansi

d. Tampilan Menu Data Pelanggan

Tampilan menu data pelanggan merupakan halaman yang menampilkan data-data pelanggan PT PLN (Persero) ULP Sengkang.

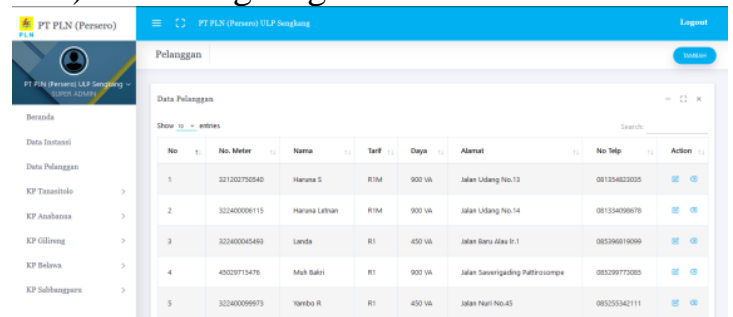

Gambar 14. Tampilan menu data pelanggan

e. Tampilan Tambah Data Pelanggan

Tampilan tambah data pelanggan merupakan halaman untuk menambah data pelanggan di Menu Data Pelanggan.

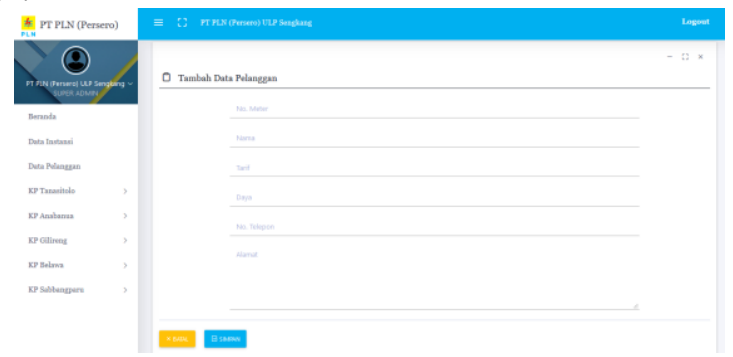

Gambar 15 Tampilan tambah data pelanggan 
f. Tampilan Laporan Masuk Bongkar Rampung

Tampilan laporan masuk bongkar rampung merupakan halaman yang menampilkan laporan masuk bongkar rampung dari kantor pelayanan.

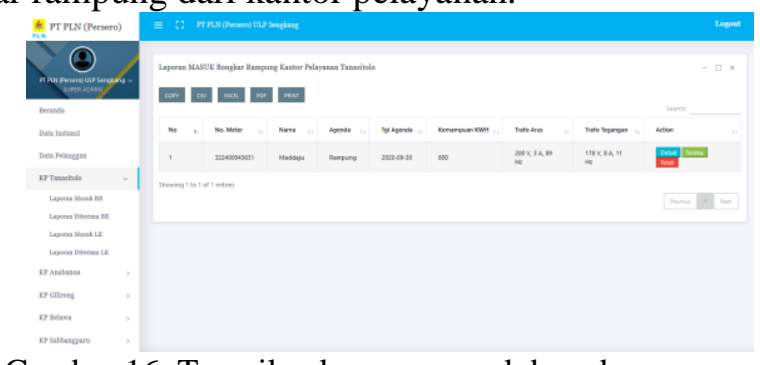

Gambar 16. Tampilan laporan masuk bongkar rampung

g. Tampilan Laporan Diterima Bongkar Rampung

Tampilan laporan diterima bongkar rampung merupakan halaman yang menampilkan laporan diterima bongkar rampung yang telah diapprove oleh PT PLN (PERSERO) ULP Sengkang.

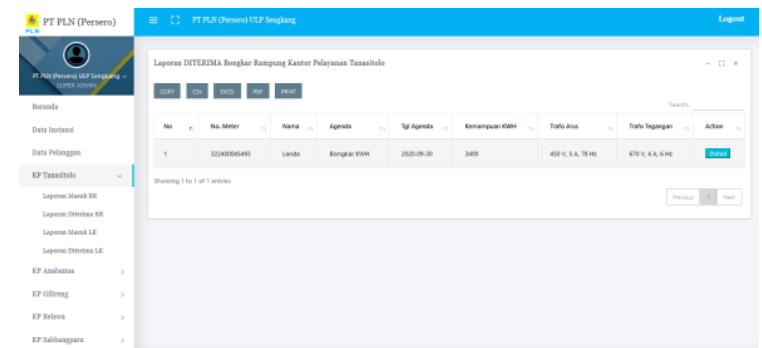

Gambar 17. Tampilan laporan diterima bongkar rampung

h. Tampilan Laporan Masuk Layanan Khusus

Tampilan laporan masuk bongkar rampung merupakan halaman yang menampilkan laporan masuk layanan khusus dari kantor pelayanan.

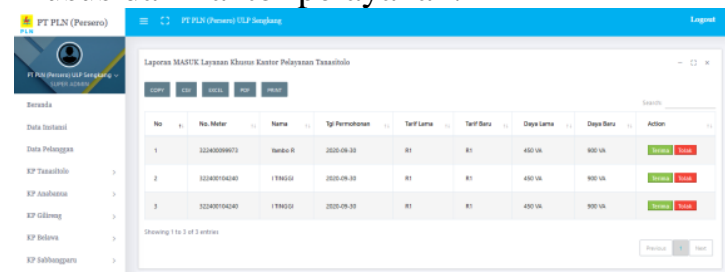

Gambar 18. Tampilan laporan masuk layanan khusus

i. Tampilan Laporan Diterima Layanan Khusus

Tampilan laporan diterima bongkar rampung merupakan halaman yang menampilkan laporan diterima layanan khusus yang telah diapprove oleh PT PLN (PERSERO) ULP Sengkang.

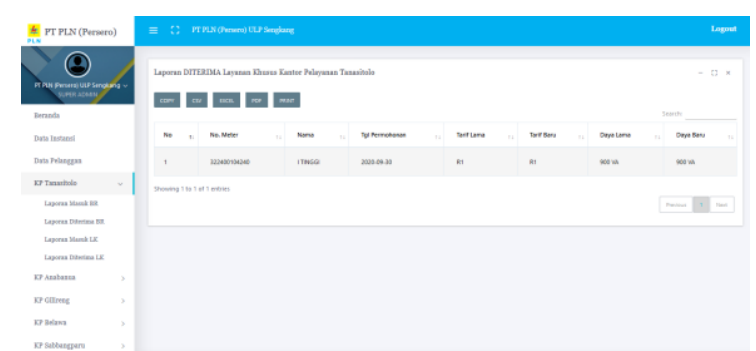

Gambar 19. Tampilan laporan diterima layanan khusus 
j. Tampilan Halaman Utama Admin

Tampilan halaman utama admin merupakan tampilan awal ketika sukses login sebagi admin/kelima Kantor Pelayanan Teknik. Halaman ini menampilkan total laporan diterima dan ditolak bongkar rampung KWh listrik dan layanan khusus.

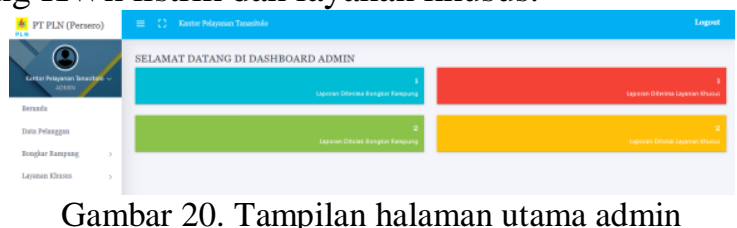

k. Tampilan Berita Acara Bongkar Rampung

Tampilan berita acara bongkar rampung merupakan halaman untuk menginput datadata berita acara bongkar rampung.

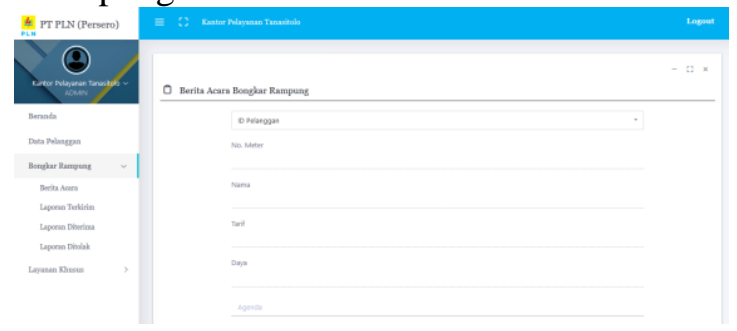

Gambar 21. Tampilan berita acara bongkar rampung

\section{Tampilan Laporan Terkirim Bongkar Rampung}

Tampilan laporan terkirim bongkar rampung merupakan halaman untuk menampilkan laporan bongkar rampung yang telah terkirim ke PT PLN(Persero) ULP Sengkang.

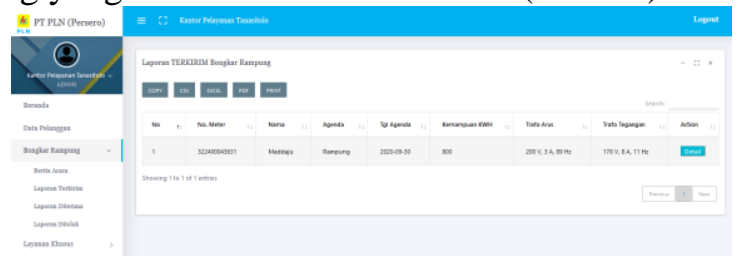

Gambar 22. Tampilan laporan terkirim bongkar rampung

m. Tampilan Laporan Diterima Bongkar Rampung

Tampilan laporan diterima bongkar rampung merupakan halaman untuk menampilkan laporan bongkar rampung yang tekah diterima oleh PT PLN (Persero) ULP Sengkang.

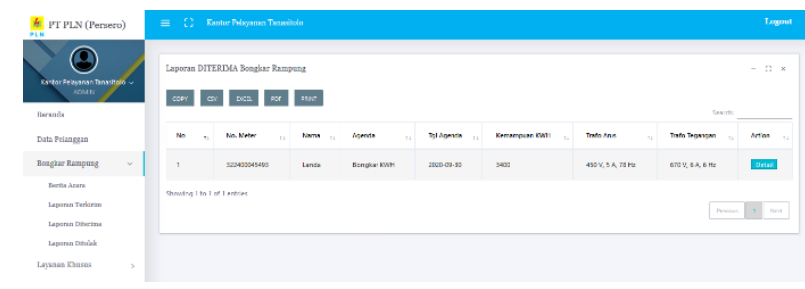

Gambar 23. Tampilan laporan diterima bongkar rampung

n. Tampilan Laporan Ditolak Bongkar Rampung

Tampilan laporan ditolak bongkar rampung merupakan halaman untuk menampilkan laporan bongkar rampung yang tekah ditolak oleh PT PLN (Persero) ULP Sengkang. 


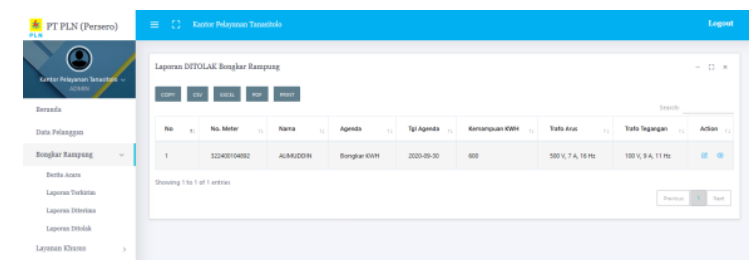

Gambar 24. Tampilan laporan ditolak bongkar rampung

o. Tampilan Berita Acara Layanan Khusus

Tampilan berita acara layanan khusus merupakan halaman untuk menginput data-data berita acara layanan khusus.

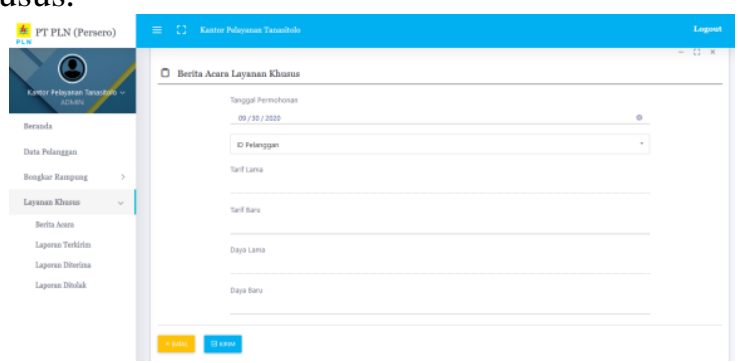

Gambar 25. Tampilan berita acara layanan khusus

p. Tampilan Laporan Terkirim Layanan Khusus

Tampilan laporan terkirim layanan khusus merupakan halaman untuk menampilkan laporan layanan khusus yang telah terkirim ke PT PLN(Persero) ULP Sengkang.

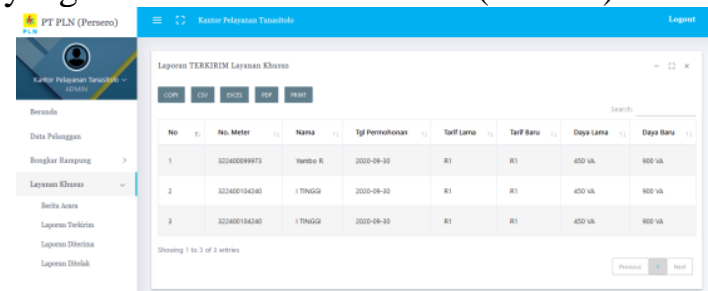

Gambar 26. Tampilan laporan terkirim layanan khusus

q. Tampilan Laporan Diterima Layanan Khusus

Tampilan laporan diterima layanan khusus merupakan halaman untuk menampilkan laporan layanan khusus yang tekah diterima oleh PT PLN (Persero) ULP Sengkang.

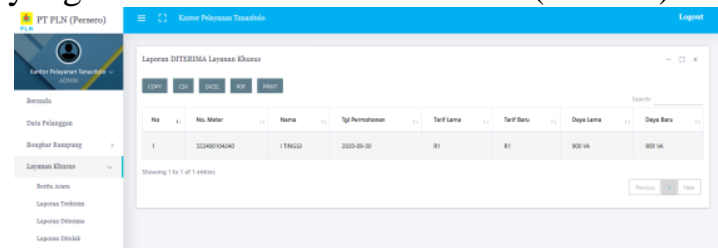

Gambar 27. Tampilan laporan diterima layanan khusus

r. Tampilan Laporan Ditolak Layanan Khusus

Tampilan laporan diterima layanan khusus merupakan halaman untuk menampilkan laporan layanan khusus yang tekah ditolak oleh PT PLN (Persero) ULP Sengkang.

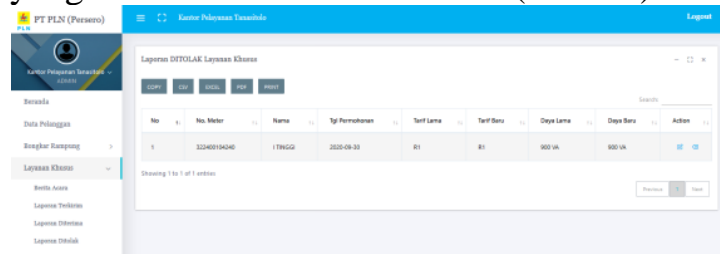

Gambar 28. Tampilan laporan ditolak layanan khusus 


\section{KESIMPULAN}

Berdasarkan hasil penelitian yang telah dilakukan, maka dapat disimpulkan bahwa aplikasi Sistem Pelaporan Bongkar Rampung KWH Listrik dan Layanan Khusus yang bertujuan untuk memudahkan PT PLN (Persero) ULP Sengkang untuk memeriksa laporan yang masuk dari pegawai-pegawai yang ada di lima kantor pelayanan yang itelah berjalan dengan baik sesuai dengan fungsinya. Serta menghemat biaya, waktu dan tenaga. Hal ini dibuktikan berdasarkan pengujian Blackbox dan kuesioner terdiri dari 10 pertanyaan yang disebar ke 30 responden maka diperoleh hasil akhir rata-rata total persentase sebanyak $81,5 \%$ yang artinya responden sangat setuju dengan adanya sistem pelaporan bongkar rampung kwh listrik dan layanan khusus berbasis web. Sistem ini sudah layak digunakan berdasarkan pernyataan sangat setuju responden terhadap pertanyaan yang diajukan tentang sisi fungsional, tampilan/interface, fitur-fitur dan lain sebagainya.

\section{DAFTAR PUSTAKA}

Aita, R.D. (2018). Model Pembacaan dan Monitoring Kwh Meter Rumah Tangga Terintegrasi Web Server. Jurnal Energi dan Kelistrikan, 2(1).

Arief, M.R. (2011). Pemrograman Web Dinamis Menggunakan Php dan Mysql. Yogyakarta: Andi.

Baiquni, A. (1995). Al-Qur'an, Ilmu Pengetahuan dan Teknologi. Yogyakarta: Dana Bhakti Wakaf.

Bentley, L.D., \& Whitten, J.L. (2009). System Analysis and Design for the Global Enterprise. New York: McGraw-Hill.

Huda, N. (2019). Kinerja Website PT PLN (Persero) Menggunakan Metode Pieces. Jurnal Sistemasi, 8(1), 78-89.

Jogiyanto. (2010). Analisis dan Desain Sistem Informasi Edisi IV. Yogyakarta: Andi.

Kadir, A. (2003). Pengenalan Sistem Informasi. Yogyakarta: Andi.

Kadir, A. (2014). Pengenalan Sistem Informasi Edisi Revisi. Yogyakarta: Andi.

Lukmanul. (2004). Cara Cerdas Menguasai Layout, Desain dan Aplikasi Web. Jakarta: PT.Elex Media Komputindo.

Mulyadi. (2013). Sistem Akuntansi Edisi 4. Yogyakarta: Salemba Empat.

Pardosi. (2004). Pengenalan Internet. Yogyakarta: Andi.

Rajab, W. (2009). Buku Ajar Epidemiologi untuk Mahasiswa Kebidanan. Jakarta: EGC.

Ramadhan, A., \& Saputra, H. (2005). Buku latihan PHP 5 dan MySQL. Jakarta: Elex Media Komputindo,

Rosa., \& M. Shalahuddin. (2011). Modul Pembelajaran Rekayasa Perangkat Lunak (Terstruktur dan Berorientasi Objek). Bandung: Modula.

Saputri, R. (2012). Perancangan Laporan Pengontrolan Kwh Listrik Menggunakan Grafik Line Pada PT PLN (Persero) Wilayah Lampung Cabang Tanjung Karang. Expert: Jurnal Manajemen Sistem Informasi dan Teknologi, 2(1), 1-8.

Sari, J.I. (2018). Rancang Bangun Sistem Informasi Monitoring Dan Perhitungan Laporan Susut Transaksi Energi Berbasis Web Pada PT PLN (Persero) Area Makassar Utara. [Skripsi]. Makassar: UIN Alauddin Makassar.

Setiadi, B. (2018). Aplikasi Monitoring Penggantian Kwh Meter Rsak Pada PT PLN (Persero). Journal of Industrial Engineering and Operation Management, 1(2), 42-45.

Sugiyono. (2011). Metode Penelitian Kuantitatif, Kualitatif dan R\&D. Bandung: Afabeta.

Sutabri, T. (2012). Konsep Sistem Informasi. Yogyakarta: Andi.

Umar, H. (2008). Cara Mudah Menyusun Skripsi dan Tesis Dilengkapi Dengan Contoh Lengkap Draft Laporan Untuk Dikritisi. Jakarta: Raja Grafindo Persada.

Veromita, J., \& Aminata, J. Analisis Permintaan Listrik di Jawa Tengah 2014-2016. Diponegoro Journal of Economics, 9(1), 95-104.

Wahyu, M.I.L. (2018). Rancang Bangun Kwh Meter Digital Sebagai Penghitung Biaya Pemakaian Energi Listrik Berbasis Arduino UNO R3. Jurnal Elektika, 1(1), 1-8. 